Review Article

\title{
Evaluation of Mental Foramen with Cone Beam Computed Tomography: A Systematic Review of Literature
}

\author{
Antoinette Pelé (iD, ${ }^{1,2}$ Pierre-Alexandre Berry $(\mathbb{D}){ }^{1,2}$ Charles Evanno (iD), ${ }^{2,3}$ \\ and Fabienne Jordana $\mathbb{( i D}^{1}$ \\ ${ }^{1}$ Oral and Maxillofacial Radiology, Dentistry Department, University Health Centre, University of Nantes, Orvault, France \\ ${ }^{2}$ Private Practice, 34 Rue Jules Verne, 44700 Orvault, France \\ ${ }^{3}$ Oral Implantology, Dentistry Department, University Health Centre, University of Nantes, Nantes, France
}

Correspondence should be addressed to Fabienne Jordana; fabienne.jordana@univ-nantes.fr

Received 23 August 2020; Revised 19 October 2020; Accepted 23 November 2020; Published 6 January 2021

Academic Editor: Lorenzo Faggioni

Copyright (c) 2021 Antoinette Pelé et al. This is an open access article distributed under the Creative Commons Attribution License, which permits unrestricted use, distribution, and reproduction in any medium, provided the original work is properly cited.

\begin{abstract}
Purpose. The aim of this systematic review is to assess whether the anatomy of mental foramen is precisely evaluable with cone beam computed tomography (CBCT) before implantation in humans. Methods. A systematic review was carried out to evaluate the anatomy of mental foramen (size, position, symmetry, anterior loop, and accessory mental foramen or multiple mental foramina). According to Preferred Reporting Items for Systematic reviews and Meta-Analyses (PRISMA) guidelines, an electronic search of three databases (Medline, Web of Science, and Cochrane Library) was undertaken until June 2020 and was supplemented by manual searching. Two reviewers will independently perform the processes of study inclusion, data extraction, and quality assessment. Systematic reviews, studies about children, and case reports were excluded. Only studies using CBCT to do preoperative evaluation were selected. Results. From 728 potentially eligible articles, 72 were included in the qualitative analysis and quantitative synthesis. This systematic review provided an assessment of the anatomy of the mental foramen. The mental foramen was located mostly between the two premolars (between $50.4 \%$ and $61.95 \%$ ) or apically to the second premolar (from 50.3\% to $57.9 \%$ ). The mean diameter of the mental foramen was bigger in males than in females; the difference between them could reach $0.62 \mathrm{~mm}$. The anterior loop seemed to be longer in males (between $0.87 \pm 1.81$ and $7.25 \pm 2.02 \mathrm{~mm}$ ) than in females (between $0.81 \pm 1.18$ and $6.52 \pm 1.63 \mathrm{~mm}$ ) and with the presence of teeth (from $0.91 \pm 1.18$ to $2.55 \pm 1.28$ for dentate people and from $0.25 \pm 0.61$ to $2.40 \pm 0.88 \mathrm{~mm}$ for edentate population). The anterior loop and the accessory mental foramina were detected more frequently with CBCT than panoramic X-ray: only between 0.0 and $48.6 \%$ AMFs detected with CBCT were also seen with panoramic images. Clinical Significance. The mental foramen (MF) is an important landmark for local anesthesia and surgical and implantology procedures. Its location, morphology, and anatomical variations need to be considered to avoid mental nerve injury. The aim of this review is to evaluate the mental foramen using CBCT through a systematic literature review to improve knowledge of this complex area for the clinician.
\end{abstract}

\section{Introduction}

The mental foramen (MF) is a strategically important landmark during implantology procedures. Its location, morphology, and anatomical variations need to be considered before surgery to avoid mental nerve injury [1].
Mental foramen is located on the mandible, a median and symmetric bone, which constitutes the low part of the face and the chin skeleton. The inferior alveolar nerve (IAN) progresses into the mandibular canal in the mandibular body on each side of the mandible. This canal opens posteriorly by the mandibular foramen and anteriorly by the mental foramen. Sometimes, small 
foramina in the surrounding area of the mental foramen are identified as accessory mental foramina (AMFs). This way, anteriorly, the IAN spreads into two branches: the mental nerve which goes out of the mandible through the mental foramen and enables the sensibility of the chin and the inferior lip while the incisive nerve stays into the mandible and enables the innervation of homolateral incisors and canine [2].

The mental nerve has different ways to reach the mental foramen. Solar et al. present a classification of intraosseous part of the mental nerve with three different types (Figure 1) [3].

The accessory mental foramina may present a continuity with the mandibular canal called "accessory branch of the mandibular canal" [5].

The area of the mental foramen shows complexity, with some anatomical particularities. The nerve can be hurt in different cases like during endodontic procedures and overfilling, teeth extractions, or surgical procedure like implantology; this could create temporary sensitive consequences for the patient similar to labiomental paresthesia $[5,6]$. This is why a dentist has to take all the precautions to protect the mental nerve during surgeries.

CBCT, specifically developed for imaging of the teeth and jaws $[7,8]$, is a low-dose scanning system [9]. CBCT use backprojection reconstructed tomography to acquire data of the whole volume of interest through a rotation of the pyramidal or conical X-ray beam and reciprocal image detector. These data are then used to generate individual slice images or 3D reconstructions [7, 9-11]. The CBCT offers a three-dimensional reconstitution of buccal cavity and different slices (axial, transversal, and sagittal) of the studied area without superposition [12].

The aim of this review is to evaluate the mental foramen using CBCT through a systematic literature review to improve knowledge of this complex area for the clinician.

\section{Materials and Methods}

The Preferred Reporting Items for Systematic Reviews and Meta-Analyses (PRISMA) system was adopted for this systematic review.

2.1. Study Protocol and Criteria. The protocol was designed to answer the following question: "do the CBCT studies evaluate the anatomic variations or individual parameters (sex, age, edentulism, and ethnic group) on the anatomy of mental foramen?"

It included studies reporting CBCT examination of the mental foramen and the surrounding area on patients before surgery or for routine examination or on cadavers. Some studies have also obtained results with panoramic radiography.

Inclusion criteria were as follows: only studies published in English in an international peer-reviewed journal were included. The observational studies had to describe the anatomy of mental foramen and the surrounding area using images obtained by CBCT.
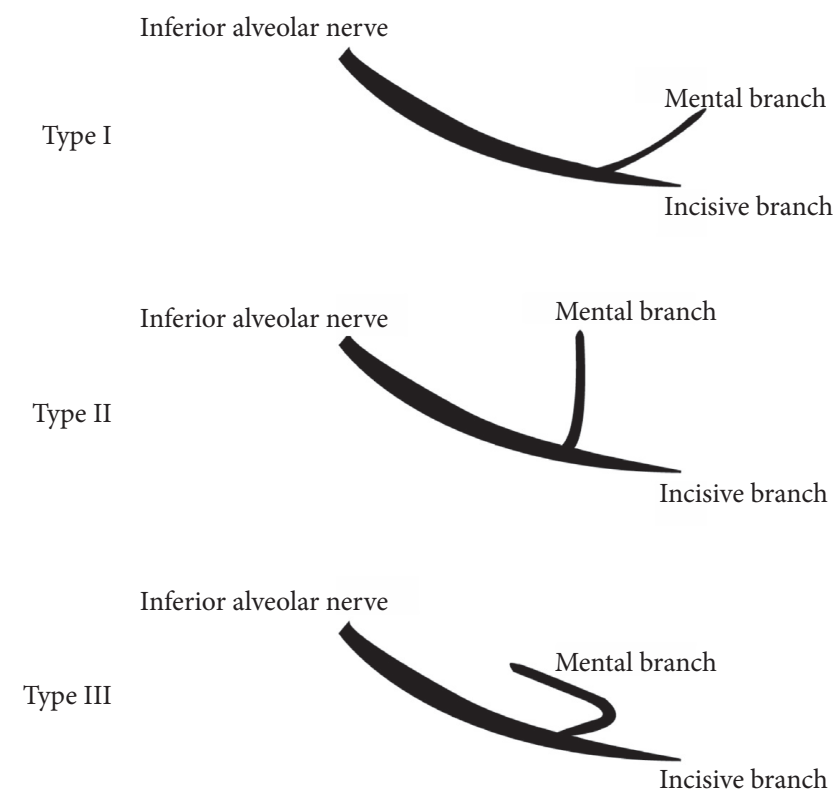

FIGURE 1: Solar et al. [3] classification of mental nerve paths. Type 1: no loop was found, and the anatomy was Y-shaped with the incisive branch usually as wide as the main branch. The mental branch leaves the inferior alveolar nerve posterior to the opening of the mental foramen [4]. Type 2: no loop was found, and the anatomy was T-shaped with the incisive branch usually as wide as the main branch. The mental branch leaves the inferior alveolar nerve perpendicular to the opening of the mental foramen [4]. Type 3: an anterior loop was found, and the anatomy was Y-shaped with the incisive branch usually as narrow as the main branch. The mental nerve branched from the inferior alveolar nerve anterior to the mental foramen [4].

Exclusion criteria were as follows: systematic reviews, studies about children, case reports, and studies using other types of computed tomography were excluded.

The following Population, Exposure to risk factor, Comparison, and Outcome (PECO) definitions were considered for systemic search:

(i) Population: studies had to include systemically cadavers or patients with CBCT examination

(ii) Exposure: no risk factor

(iii) Comparison: the specific comparisons investigated were anatomic variations or individual parameters (sex, age, edentulism, and ethnic group) on the evaluation of the anatomy of mental foramen

(iv) Outcome measures: characteristics of mental foramen (size, position, symmetry, accessory mental foramen, or multiple mental foramina)

2.2. Search Strategy. A literature search was performed in MEDLINE via the PubMed database of the US National Library of Medicine, Web of Science, and Cochrane Library databases as well as a hand search of other literature to identify articles of potential relevance. The search included articles accepted for publication from 2008 up to June 2020. 
Previously published review articles on similar topics were also analyzed to assess potentially relevant publications.

The following keywords were used for this purpose:

Mental foramen OR mental foramina

AND CBCT OR Cone Beam Computed Tomography

2.3. Quality Assessment. Quality assurance was developed by independent screening by two reviewers (AP and $\mathrm{PAB}$ ) according to Khan et al. [13]. When disagreement arose in the selection and eligibility, it was resolved by discussion between the two reviewers.

\section{Results}

The initial search of the literature up to June 2020 yielded 728 potentially suitable papers. Two independent reviewers $(\mathrm{AP}$ and $\mathrm{PAB})$ analyzed titles and abstracts during the first stage of screening. Irrelevant articles and duplicates were discarded. Additional manual searching of reference lists in the papers selected as well as in a number of review articles was performed to source further relevant publications. Eighty-four full-text articles were assessed for eligibility. The full texts of the articles were read to determine whether the studies fulfilled the predetermined inclusion criteria. Seventy-two studies fulfilled the inclusion criteria and twelve were excluded (Figure 2). Following the exclusion of reviews, children studies, case reports, and studies using other types of computed tomography, 72 publications remained fully eligible for this review.

The $\kappa$ value for interviewer agreement for study inclusion was 0.95 for titles and abstracts and 1.00 for full-text articles, indicating strong agreement.

Data was collated $[4,5,12,14-82]$ into tables (Tables $1-5$ and Supplementary Tables 1-3) and grouped according to the anatomical characteristics studied. Data synthesis was performed based on the evidence tables alone, and the data was further interpreted.

\subsection{The Mental Foramen}

3.1.1. Localization. Mental foramina (MFs) were equidistant from the midline of the mandible [35-37]. The mean distance did not vary much from a study to another, from around $23 \mathrm{~mm}$ to $26 \mathrm{~mm}[35,37]$. The interforaminal distance seemed to correspond to the double of these values, about between $46.5 \pm 5 \mathrm{~mm}$ and $51.4 \pm 0.6 \mathrm{~mm}$ [35, 37]. Moreover, according to Parnia et al., the mental foramen was located around $5 \mathrm{~mm}$ away from the lingual border of the mandible, and according to von Arx et al., the shortest distance between MF and a tooth is around $5 \mathrm{~mm}[15,36]$.

When looking vertically, the MF appeared to be approximately in the middle of the mandible regardless of the side with a longer distance between the MF and mandible borders in men. The mean distance between MF and inferior border of the mandible ranged from around $10 \mathrm{~mm}$ and $15 \mathrm{~mm}[16,38]$. This distance was longer in male. For example, according to Gungor et al., the mean distance was
$13.35 \pm 2.1 \mathrm{~mm}$ in men, whereas it was $12.0 \pm 1.8 \mathrm{~mm}$ in women [39].

The mean distance between MF and superior border of the mandible ranged from $11.2 \pm 1.99$ to $14.3 \mathrm{~mm}[12,22]$. This distance was also longer in males than in females $[12,39,40]$. For example, Gungor et al. measured $14.03 \pm 2.85 \mathrm{~mm}$ in males against $12.53 \pm 2.54 \mathrm{~mm}$ in females [39].

3.2. No Significant Difference Was Found between Right and Left Sides. The MF was located mostly between the two premolars (between $50.4 \%$ and $61.95 \%$ ) or apically to the second premolar (PM2) (from 50.3\% to 57.9\%) $[15,16,18-22,25,26]$. Then, it was situated between the PM2 and the first molar (M1) (between $16.7 \%$ and 19.4\%) or apically to the M1 (from $6.7 \%$ to $10.7 \%$ ) and exceptionally before the PM1 or between M1 and second molar $[12,16,19,20,22,24]$. Sex and side did not seem to have influence on the MF location in relation to the teeth. According to Chen et al., the presence of an anterior loop of the inferior alveolar nerve (AL) could have an influence on the position of MF to the teeth [16]. Indeed, at the majority position, without AL, the MF was found at $51.7 \%$ between PM1 and PM2, whereas when there was an AL, it was found at $73.3 \%$ apically to the PM2. On the contrary, in Krishnan et al.'s study [24], no significant difference was noticed (Table 1).

3.2.1. Shape. The majority of the shapes of MF in the general population were round (between $61.57 \%$ and $72.66 \%$ ) or oval (between $60.7 \%$ and $73.1 \%$ ) [18, 24, 41-44], and less frequently, it could be irregular (11.14\%) [25]. None of the individual parameters studied seemed to have influence of the MF shape [18, 24, 41-44].

3.2.2. Diameter. The mean diameter of mental foramen ranged from $2.08 \pm 0.53 \mathrm{~mm}$ to $4.44 \pm 1.13 \mathrm{~mm}$. Nevertheless, it was around $3 \mathrm{~mm}$ most of the time [21, 43]. The mean diameter was superior in males than in females in all the articles studied; the difference between them could reach $0.62 \mathrm{~mm}[12,16,25,38-40,45-47]$. Moreover, when there was an accessory mental foramen (AMF) ipsilateral to the MF, its diameter was smaller (Supplementary Table 2) $[18,40,48-50]$. The diameter of AMF was smaller than mental foramen diameter, around $1.5 \mathrm{~mm}$ on average. It ranged from $0.87 \pm 0.24 \mathrm{~mm}$ to $1.9 \pm 0.6 \mathrm{~mm}[24,40]$.

3.2.3. Area. The mean area of $\mathrm{MF}$ ranged from $9.41 \pm 4.58 \mathrm{~mm}^{2}$ to $13.1 \pm 7.00 \mathrm{~mm}^{2}$. MF area was larger than AMF area [51, 52]. According to Muinelo-Lorenzo et al. and Iwanaga et al., the MF ipsilateral to an AMF had a smaller area $\left(9.0 \pm 5,2\right.$ and $\left.12.9 \pm 8.0 \mathrm{~mm}^{2}\right)$ than the area measured in general $\left(10.62 \pm 5.00\right.$ and $\left.13.1 \pm 7.0 \mathrm{~mm}^{2}\right)[18,51]$. On the contrary, MF was bigger on the contralateral side of an AMF or when a patient had no AMF than in general $(11.36 \pm 4.5$ and $\left.14.3 \pm 7.2 \mathrm{~mm}^{2}\right)[18,51]$. 


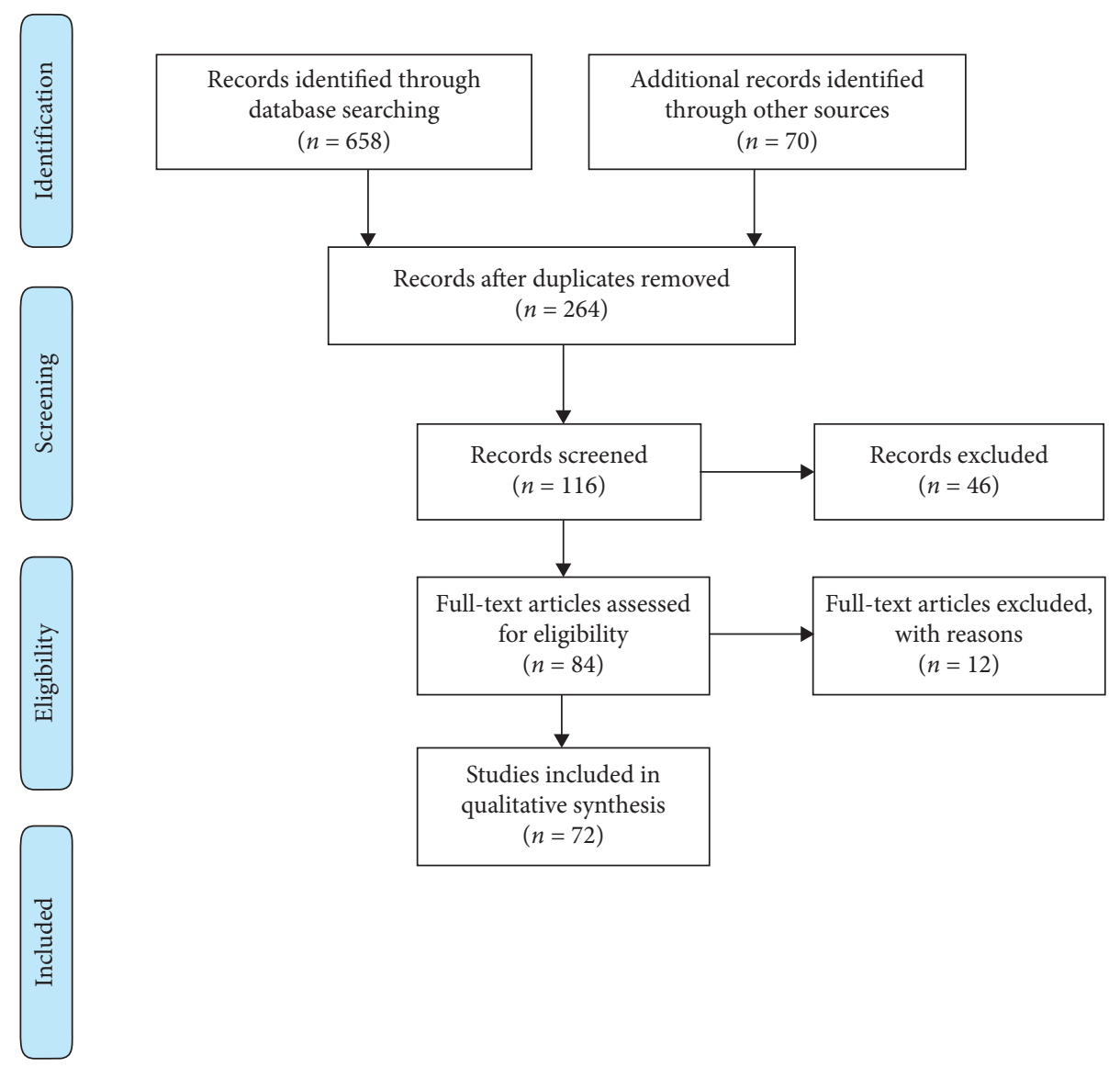

FIgURE 2: Preferred Reporting Items for Systematic Reviews and Meta-Analyses (PRISMA) flow diagram demonstrating the results of the systematic literature search.

TABLE 1: Location of the mental foramen (MF) in relation to adjacent teeth $n$ MF (\%).

\begin{tabular}{|c|c|c|c|c|c|c|c|c|}
\hline Articles & $\begin{array}{l}\text { Anterior to } \\
\text { PM1 }\end{array}$ & $\begin{array}{l}\text { In line with } \\
\text { PM1 }\end{array}$ & $\begin{array}{l}\text { Between PM1 } \\
\text { and PM2 }\end{array}$ & $\begin{array}{c}\text { In line with } \\
\text { PM2 }\end{array}$ & $\begin{array}{l}\text { Between PM2 } \\
\text { and M1 }\end{array}$ & $\begin{array}{l}\text { In line with M1 (often } \\
\text { to the mesial root) }\end{array}$ & $\begin{array}{l}\text { Between M1 } \\
\text { and M2 }\end{array}$ & Total \\
\hline$[14]$ & $0(0.0)$ & $18(4.8)$ & $231(59.8)$ & $120(30.4)$ & $16(4.2)$ & $1(0.3)$ & $0(0.0) \dagger$ & $\begin{array}{c}386 \\
(100)\end{array}$ \\
\hline$[15]$ & $0(0.0)$ & $7(4.2)$ & $94(56)$ & $60(35.7)$ & $7(4.2)$ & $0(0.0)$ & $0(0.0)$ & $\begin{array}{c}168 \\
(100)\end{array}$ \\
\hline [16] & $\left(0.0^{\dagger}\right)$ & $(3.33)$ & $(51.67)$ & $(40.83)$ & $(4.17)$ & $\left(0.0^{\dagger}\right)$ & $\left(0.0^{\dagger}\right)$ & (100) \\
\hline & & $\left(6.66^{\dagger}\right)^{\ddagger}$ & & $(73.33)^{\ddagger}$ & $0^{\ddagger}$ & - & - & $\begin{array}{c}(100) \\
106\end{array}$ \\
\hline [17] & & $57(53.8)$ & & $1(1)$ & & $48(45.3)$ & & $\begin{array}{l}106 \\
(100)\end{array}$ \\
\hline [18] & $0(0.0) \dagger$ & $32(5)$ & $161(25.3)$ & $369(57.9)$ & $58(9.1)$ & $17(2.7)$ & $0(0.0) \dagger$ & $\begin{array}{c}637 \\
(100)\end{array}$ \\
\hline [19] & $0(0.0)$ & $1(2.6)$ & $9(23.1)$ & $22(56.4)$ & 7 (17.9) & $0(0.0)$ & $0(0.0) \dagger$ & $39(100)$ \\
\hline [20] & $0(0.0) \dagger$ & $0 \dagger(0.0 \dagger)$ & $103(33.0)$ & $157(50.3)$ & $52(16.7)$ & $0(0.0) \dagger$ & $0(0.0) \dagger$ & $\begin{array}{c}312 \\
(100)\end{array}$ \\
\hline [21] & $(0.0) \dagger$ & $(5.0)$ & $(25.3)$ & $(57.9)$ & $(0.0) \dagger$ & $(2.7)$ & $(9.1)$ & (100) \\
\hline [22] & $0(0.0) \dagger$ & $62(10.3)$ & $179(29.6)$ & $319(52.8)$ & $36(6)$ & $8(1.3)$ & $0(0.0) \dagger$ & $\begin{array}{c}604 \\
(100)\end{array}$ \\
\hline [23] & $0(0.0) \dagger$ & $(7.03)$ & $(73.39 \dagger)$ & $(17.74)$ & $(1.83 \dagger)$ & $(0.0 \dagger)$ & $(0.0 \dagger)$ & (100) \\
\hline [12] & $1(0.6)$ & $18(10.7)$ & $75(44.4)$ & $69(40.8)$ & $5(3.0)$ & $1(0.6)$ & $0(0.0) \dagger$ & $\begin{array}{c}169 \\
(100)\end{array}$ \\
\hline [24] & 0.0 & (1.9) & $(43.5)$ & $(34.3)$ & $(19.4)$ & $(0.9)$ & $(0.0 \dagger)$ & $(100)$ \\
\hline & - & - & $(41.2)^{\ddagger}$ & $(37.3)^{\ddagger}$ & - & - & - & $(100)$ \\
\hline [25] & $0(0.0)$ & $5(3.6)$ & $70(50.4)$ & $57(41.0)$ & & $7(5.0)$ & & $\begin{array}{c}139 \\
(100)\end{array}$ \\
\hline [26] & $2(0.25) \dagger$ & $66(8.26) \dagger$ & $495(61.95) \dagger$ & $219(27.41) \dagger$ & $11(1.38) \dagger$ & $6(0.75) \dagger$ & - & $\begin{array}{c}799 \dagger \\
(100)\end{array}$ \\
\hline
\end{tabular}

PM1: first premolar, PM2: second premolar, M1: first molar, and M2: second molar. ${ }^{\dagger}$ Values calculated based on data from publications. ${ }^{\ddagger}$ In the presence of an anterior loop of the inferior alveolar nerve. 
TABLe 2: Path of mandibular canal (MC) to the mental foramen $n$ MC (\%).

\begin{tabular}{lccc}
\hline Articles & Straight & Perpendicular/vertical & Anterior loop \\
\hline$[27]$ & $329(33.30) \dagger$ & $442(44.74) \dagger$ & $217(21.96) \dagger$ \\
{$[22]$} & $279(46.2)$ & $233(38.6)$ & $92(15.2)$ \\
\hline
\end{tabular}

${ }^{\dagger}$ Values calculated based on data from publications.

TABle 3: Distribution of mental nerve paths $n$ (\%) according Solar et al. [3] classification.

\begin{tabular}{lccccc}
\hline Articles & Type I (Y) & Type II (T) & Type III (AL + Y) & Others (AL) & Number of sites \\
\hline$[4]$ & $48(8.6)$ & $178(31.9)$ & $332(59.5)$ & - & $358(100)$ \\
{$[34]$} & $15(10.6)$ & $39(27.5)$ & $50(35.2)$ & $142(100)$ \\
\hline
\end{tabular}

AL: anterior loop.

TABLE 4: Comparison between cone beam computed tomography (CBCT) and panoramic radiograph (PAN) in measuring distances (mm).

\begin{tabular}{|c|c|c|c|c|c|c|c|c|c|c|}
\hline \multirow{3}{*}{ Articles } & \multicolumn{4}{|c|}{$\begin{array}{l}\text { Mean distance MF-midline of the } \\
\text { mandible }\end{array}$} & \multirow{2}{*}{\multicolumn{2}{|c|}{$\begin{array}{l}\text { Mean } \\
\text { interforaminal } \\
\text { distance }\end{array}$}} & \multirow{2}{*}{\multicolumn{2}{|c|}{ Mean length of the AL }} & \multirow{2}{*}{\multicolumn{2}{|c|}{$\begin{array}{c}\text { Mean distance } \\
\text { AL-inferior border of the } \\
\text { mandible }\end{array}$}} \\
\hline & \multicolumn{2}{|c|}{ Right side } & \multicolumn{2}{|c|}{ Left side } & & & & & & \\
\hline & СВCT & PAN & CBCT & PAN & $\mathrm{CBCT}$ & PAN & CBCT & PAN & CBCT & PAN \\
\hline [35] & $23 \pm 2.8$ & $21.3 \pm 3.5$ & $23 \pm 2.4$ & $21 \pm 3.9$ & $46.5 \pm 5$ & $41.9 \pm 7.1$ & - & - & - & - \\
\hline [31] & - & - & - & - & - & - & $1.59 \pm 0.93$ & $2.82 \pm 0.91$ & $11.43 \pm 1.81$ & $11.64 \pm 1.81$ \\
\hline [32] & - & - & - & - & - & - & $2.79 \pm 0.82^{\dagger}$ & $3.03 \pm 0.92^{\dagger}$ & - & - \\
\hline
\end{tabular}

MF: mental foramen. AL: anterior loop. ${ }^{\dagger}$ Values calculated based on data from publications.

TABLE 5: Comparison between cone beam computed tomography (CBCT) and panoramic radiograph (PAN) for the visualization of anatomical structures.

\begin{tabular}{|c|c|c|c|c|}
\hline \multirow[t]{2}{*}{ Articles } & \multicolumn{2}{|c|}{$\begin{array}{l}\text { Detection of accessory mental foramina } \\
\text { (AMFs) } n \text { AMFs (\%) }\end{array}$} & \multicolumn{2}{|c|}{ Visualization of the anterior loop (AL) $n$ AL (\%) } \\
\hline & СBCT & PAN & $\mathrm{CBCT}$ & PAN \\
\hline [28] & $37(100.00)$ & $18(48.60)$ & - & - \\
\hline [29] & $4\left(100.00^{\dagger}\right)$ & $0\left(0^{\dagger}\right)$ & - & - \\
\hline [30] & $19\left(100.00^{\dagger}\right)$ & $3\left(15.79^{\dagger}\right)$ & - & - \\
\hline [31] & - & - & $40(48.80) /$ patient & $30(36.60) /$ patient \\
\hline [18] & $(100.00)$ & $(45.83)$ & - & - \\
\hline [32] & - & - & $60^{1}\left(30.30^{\dagger}\right) /$ side & $41^{1}\left(20.10^{\dagger}\right) /$ side \\
\hline [33] & - & - & $67(37.20) /$ side & $102(56.75) /$ side \\
\hline
\end{tabular}

${ }^{\dagger}$ Values calculated based on data from publications.

3.2.4. Opening Angle. The mean opening angle of $\mathrm{MF}$ ranged from $45.65 \pm 10.8$ and $55.84 \pm 12.16$ degrees $[43,45]$. According to Çağlayan et al., there was a difference between sides (about $53.58 \pm 11.39^{\circ}$ on right sides and $58.09 \pm 12.93^{\circ}$ on left sides) [53]. Moreover, in the same study, the angle varied much more: $51.14 \pm 8.90^{\circ}$ and $54.66 \pm 12.48^{\circ}$ on right sides and $58.15 \pm 13.40^{\circ}$ and $58.07 \pm 12.73^{\circ}$ on left ones, respectively, in men and in women [53].

\subsection{The Accessory Mental Foramen}

3.3.1. Prevalence and Repartition. The prevalence of AMFs ranged from $2 \%$ to $26 \%$ among populations studied $[26,54]$. For the sides, the maximum prevalence was $23.79 \%$, which was quite the same than in the populations $[26,54,55]$, more common in men $[17,21,26,29,50,51,54,56-59]$. The AMF was seen more often on the right side of a patient; indeed, out of 10 studies, only three found more left sides with AMF than right ones $[50,51,58]$. Two studies found the same number of AMF on the right and left sides [26, 29, 54].

The AMF was more often found unilaterally in the studies, with a maximum of only 13 patients with AMFs on both sides in Aytugar et al.'s study [50]. Most of the time, the authors detected one to two AMFs per patient $[5,17,24,29,40,49]$.

3.3.2. Diameter. The mean diameter of AMF ranged from $0.87 \pm 0.24 \mathrm{~mm}$ to $1.9 \pm 0.6 \mathrm{~mm}$, but it was around $1.5 \mathrm{~mm}$ most of the time $[24,40]$. So, the AMF was smaller than the MF, about a half of it. For example, according to Gümüsok et al. [47], the mean horizontal and vertical diameters of MFs were, respectively, $2.80 \pm 0.99 \mathrm{~mm}$ and $3.11 \pm 0.89$, whereas there were $1.27 \pm 0.40$ and $1.50 \pm 0.63 \mathrm{~mm}$ for AMFs. No 
difference was found between the sex of the patient or sides on the AMF mean diameter (Supplementary Table 2).

3.3.3. Area. The mean area of AMF ranged from $1.20 \pm 1.10 \mathrm{~mm}^{2}$ to $1.8 \pm 1.4 \mathrm{~mm}^{2}[51,52]$.

3.3.4. Localization. The AMF position the most seen was posteroinferior to the MF. Indeed, most of AMFs were found at this position in 8 studies out of $17[18,30,40,47$, $50,54,57,60]$. However, it was not the first position in each study; for example, some authors did not find any AMF at this position [29]. The AMF was located from around $2.54 \pm 1.09 \mathrm{~mm}$ to $8.7 \pm 4.3 \mathrm{~mm}$ away from the $\mathrm{MF}$, and $\mathrm{AMF}$ was situated in a radius of $1 \mathrm{~cm}$ around the $\mathrm{MF}[49,51]$. According to Sisman et al., eight AMF showed continuity with the mandibular canal out of 14 [54]. Among them, two were connected with the AL and six were directly connected to the mandibular canal posteriorly to the MF.

3.4. The Mandibular Canal. Two articles mentioned three paths of the MC to the mental foramen [22, 27]. First, there were "straight" type and "perpendicular" or "vertical" type and then less frequently the AL with $15.2 \%$ and $21.96 \%$ (Table 2) [22, 27].

According Solar et al.'s classification, the paths of the MC were in frequency order: type III $(A L+Y)$, type II $(T)$, and type I (Y) [3, 4, 34] (Table 3). Moreover, they had another type called "others," including other forms of AL seen at $26.8 \%$ [34].

\subsection{The Anterior Loop of the Inferior Alveolar Nerve}

3.5.1. Prevalence and Repartition. Within the different studies, the prevalence of the AL ranged from $10.4 \%$ to $94 \%$ and from $10 \%$ to $86 \%$ among sides observed [61-64]. The sex of the patient did not seem to have a significant influence on it. However, ALs were situated mostly on the right side of patient in six studies out of eight (that looked at this parameter) $[4,27,32,36,65,66]$. The AL could be found unilaterally or bilaterally with no predominance of one or another.

3.5.2. Length. The mean AL length ranged from $0.89 \pm 1.17 \mathrm{~mm}$ to $7.61 \pm 1.81 \mathrm{~mm}[16,38]$. Among the extreme values, except for a minimal length of $0.0 \mathrm{~mm}$ meaning the absence of the AL, the smallest $\mathrm{AL}$ measured within the studies had a length of $0.15 \mathrm{~mm}$, whereas the longest $\mathrm{AL}$ was equal to about $9.37 \mathrm{~mm}$ according to Yoon and al. $[14,52,67]$. The AL seemed to be longer in males (between $0.87 \pm 1.81$ and $7.25 \pm 2.02 \mathrm{~mm}$ ) than in female (between $0.81 \pm 1.18$ and $6.52 \pm 1.63 \mathrm{~mm}$ ); indeed, there were only two studies out of thirteen with a mean AL length bigger in females $[16,27]$. The presence of teeth could be in favor of longer average length (from $0.91 \pm 1.18$ to $2.55 \pm 1.28$ for dentate people and from $0.25 \pm 0.61$ to $2.40 \pm 0.88 \mathrm{~mm}$ with edentulous) $[14,67,68]$. Finally, the lengths measured on the left sides tended to be smaller except for Uchida et al. and Koivisto et al., who measured, respectively, $2.1 \pm 1.9 \mathrm{~mm}$ and $3.5 \mathrm{~mm}$ on average against $1.7 \pm 1.3 \mathrm{~mm}$ and $2.5 \mathrm{~mm}$ on the right sides (Supplementary Table 3) $[62,68]$.

3.5.3. Angle. Only one study measured the angle of the AL. Chen et al. found a mean angle of $19.13 \pm 26.89^{\circ}$ in the population [16]. This angle appeared to be bigger on the right sides than on left ones and in females $\left(25.21 \pm 28.89^{\circ}\right)$ than in males $\left(13.06 \pm 23.43^{\circ}\right)$.

3.6. Comparison between CBCT and PAN. Mean distances between $\mathrm{MF}$ and midline of the mandible and interforaminal mean distance measured with CBCT were greater than those measured with PAN. For example, Madrigal et al. [35] measured $46.5 \pm 5 \mathrm{~mm}$ between the two MFs with CBCT, while they measured $41.9 \pm 7.1 \mathrm{~mm}$ with PAN. It was the opposite for the AL mean length (Table 4) [31, 32, 35].

Moreover, AL and AMFs were detected more frequently with CBCT. For example, according to Vujanovik-Eskenazi et al., the AL was seen in 40 patients with CBCT against 30 with PAN [31]. Only $15.79 \%$ of AMFs detected with CBCT were also seen with PAN according to Neves et al. [30] (Table 5), and this could be explained by the small diameter of AMF (often inferior to $1 \mathrm{~mm}$ ) and was spot with difficulty on panoramic radiograph [5].

\section{Discussion}

The mental foramen is a strategically important landmark during surgical procedures [1]. Its location, number of foramina, and possibility of anterior loop of the mental nerve or AMF being present need to be considered before surgery to avoid mental nerve injury. This article systematically reviews the literature with respect to the mental foramen to reduce unintentional damage to the mental nerve.

The damage to mental foramen or inferior alveolar nerve during oral surgery or implant placement is a serious complication [83]. The incidence of mental neurosensory disturbances resulting from orthodontic, periodontal, and surgical procedures cannot be determined [84]. Juodzbalys et al. reported the complication incidence, which varies from $0 \%$ to $40 \%$, of implant related inferior alveolar nerve (IAN) injuries [83]. The IAN is the most commonly injured nerve (64.4\%), followed by the lingual nerve $(28.8 \%)$ [85]. The damages could be range from mild paresthesia or dysesthesia to complete anesthesia and/or pain [86]. Many functions (speech, eating, kissing, drinking, etc.) will be affected [87]. The damage can result from the traumatic local anaesthetic injections or during the dental implant site osteotomy or placement or direct injury with scalpel with extreme alveolar process resorption [83].

CBCT allows collecting extensive informations about the $\mathrm{MF}$ anatomy, its environment and anatomical variations that can exist when some clinical parameters vary as sex, side or dental status.

When comparing two- and three-dimensional imaging, some differences were noticed. The average distances between MF and midline and between the mental foramina measured with cone beam were greater than those measured with PAN [35]. It was the contrary for AL lengths [31, 32]. CBCT 
overcomes certain limitations of two-dimensional imaging, such as distortion, magnification, and superimposition [88]. CBCT-reformatted panoramic images have been shown to be superior to PAN identifying the mandibular canal, because these images are free of magnification and superimposition [89]. So, according to Aminoshariae et al., CBCT is better in detecting anatomical particularities of each patient [90]. The authors supported the use of CBCT to evaluate the patient anatomy to avoid nerve injury before surgery [91].

To avoid nerve injury during surgery in the foraminal area, guidelines were developed based on the literature with respect to verifying the position of the mental foramen and validating the presence of an anterior loop of the mental nerve according to Greenstein and Tarnow [1]. The practitioner must be aware of the mental area anatomy and morphology before undertaking any treatment [84]. According to Juodzbalys et al. [83], the best way to prevent these damages is to have a clear three-dimensional vision of the jaw: proper presurgery planning, timely diagnosis, and treatment are the key to avoiding nerve sensory disturbances management. These guidelines included leaving a $2 \mathrm{~mm}$ safety zone between an implant and the coronal aspect of the nerve, three-dimensional radiographic evaluation, or surgical corroboration of the mental foramen's position [1].

Clinicians must also know the opening angle of the MF when operating on this area. For example, the diameter and length of an implant could be modified according to this angle. A smaller or thinner implant could be necessary when the opening angle of the MF increases since it means that the MF opens at a higher level than the mandibular canal one.

\section{Conclusion}

In dentistry, the acknowledgment of the anatomy of the oral cavity is necessary to treat patients correctly, especially for local anesthesia, in surgery or implantology consequently risking damage to critical structures, such as nerves and blood vessels. However, each person presents particularities, the anatomic variations, increasing the risks during our intervention. So, the clinician has to detect them during the preoperative phase to organize the patient treatment.

In the systematic review, the advantages of the CBCT technique were studied to analyze a surgical zone at anatomical risk within the mandible, that is, the mental foramen. The mental foramen was located mostly between the two premolars (between $50.4 \%$ and $61.95 \%$ ) or apically to the second premolar (from $50.3 \%$ to $57.9 \%$ ). The mean diameter of the mental foramen was bigger in males than in females, with a difference reaching $0.62 \mathrm{~mm}$. The mean $\mathrm{AL}$ length ranged from $0.89 \pm 1.17 \mathrm{~mm}$ to $7.61 \pm 1.81 \mathrm{~mm}$. The prevalence of the AL ranged from $10.4 \%$ to $94 \%$, and from $10 \%$ to $86 \%$ among sides observed. The AMF, most seen in posteroinferior location to the $\mathrm{MF}$, was situated from around $2.54 \pm 1.09 \mathrm{~mm}$ to $8.7 \pm 4.3 \mathrm{~mm}$ away from the MF.

\section{Data Availability}

Data are included within the article.

\section{Conflicts of Interest}

The authors declare that they have no conflicts of interest.

\section{Supplementary Materials}

Supplementary Material 1: design of selected publications. Supplementary Material 2: mean diameter of mental foramen and accessory mental foramen $(\mathrm{mm})$. Supplementary Material 3: mean length of the anterior loop (mm). (Supplementary Materials)

\section{References}

[1] G. Greenstein and D. Tarnow, "The mental foramen and nerve: clinical and anatomical factors related to dental implant placement: a literature review," Journal of Periodontology, vol. 77, no. 12, pp. 1933-1943, 2006.

[2] T. Kawai, I. Sato, R. Asaumi, and T. Yosue, "Cone-beam computed tomography and anatomical observations of normal variants in the mandible: variant dentists should recognize," Oral Radiology, vol. 34, no. 3, pp. 189-198, 2018.

[3] P. Solar, C. Ulm, G. Frey, and M. Matejka, "A classification of the intraosseous paths of the mental nerve," International Journal of Oral Maxillofacial Implants, vol. 9, pp. 339-344, 1994.

[4] A. Demir, E. Izgi, and F. Pekiner, "Anterior loop of the mental foramen in a Turkish subpopulation with dentate patients: a cone beam computed tomography study," Müsbed, vol. 5, pp. 231-238, 2015.

[5] K. Katakami, A. Mishima, K. Shiozaki, S. Shimoda, Y. Hamada, and K. Kobayashi, "Characteristics of accessory mental foramina observed on limited cone-beam computed tomography images," Journal of Endodontics, vol. 34, no. 12, pp. 1441-1445, 2008.

[6] X. Wang, K. Chen, S. Wang, S. K. Tiwari, L. Ye, and L. Peng, "Relationship between the mental foramen, mandibular canal, and the surgical access line of the mandibular posterior teeth: a one-beam computed tomographic analysis," Journal of Endodontics, vol. 43, no. 8, pp. 1262-1266, 2017.

[7] Y. Arai, E. Tammisalo, K. Iwai, K. Hashimoto, and K. Shinoda, "Development of a compact computed tomographic apparatus for dental use," Dentomaxillofacial Radiology, vol. 28, no. 4, pp. 245-248, 1999.

[8] P. Mozzo, C. Procacci, A. Tacconi, P. T. Martini, and I. A. Andreis, "A new volumetric CT machine for dental imaging based on the cone-beam technique: preliminary results,” European Radiology, vol. 8, pp. 1558-1564, 1999.

[9] A. Dawood, S. Patel, and J. Brown, "Cone beam CT in dental practice," British Dental Journal, vol. 207, pp. 23-28, 2009.

[10] P. Sukovic, "Cone beam computed tomography in craniofacial imaging," Orthodontics \& Craniofacial Research, vol. 6, pp. 31-36, 2003.

[11] J. K. Mah, R. A. Danforth, A. Bumann, and D. Hatcher, "Radiation absorbed in maxillofacial imaging with a new dental computed tomography device," Oral Surgery, Oral Medicine, Oral Pathology, Oral Radiology, and Endodontology, vol. 96, no. 4, pp. 508-513, 2003.

[12] R. Dos Santos Oliveira, M. Rodrigues Coutinho, and F. Kühl Panzarella, "Morphometric analysis of the mental foramen using cone-beam computed tomography," International Journal of Dentistry, vol. 2018, Article ID 4571895, 7 pages, 2018. 
[13] K. S. Khan, G. ter Riet, and J. Popay, "Stage II: conducting the review. Phase 5: study quality assessment," in Undertaking Systematic Reviews of Research on Effectiveness, K. S. Khan, G. ter Tiet, and J. Glanvill, Eds., pp. 1-20, University of York, York (UK), 2 edition, 2001.

[14] M. B. Rosa, B. S. Sotto-Maior, V. de Carvalho Machado, and C. E. Francischone, "Retrospective study of the anterior loop of the inferior alveolar nerve and the incisive canal using cone beam computed tomography," The International Journal of Oral \& Maxillofacial Implants, vol. 28, no. 2, pp. 388-392, 2013.

[15] T. von Arx, M. Friedli, P. Sendi, S. Lozanoff, and M. M. Bornstein, "Location and dimensions of the mental foramen: a radiographic analysis by using cone-beam computed tomography," Journal of Endodontics, vol. 39, no. 12, pp. 1522-1528, 2013.

[16] Z. Chen, D. Chen, L. Tang, and F. Wang, "Relationship between the position of the mental foramen and the anterior loop of the inferior alveolar nerve as determined by cone beam computed tomography combined with mimics," Journal of Computer Assisted Tomography, vol. 39, no. 1, pp. 86-93, 2015.

[17] P. Carruth, J. He, B. W. Benson, and E. D. Schneiderman, "Analysis of the size and position of the mental foramen using the CS 9000 cone-beam computed tomographic unit," Journal of Endodontics, vol. 41, no. 7, pp. 1032-1036, 2015.

[18] J. Muinelo-Lorenzo, J. Suárez-Quintanilla, A. FernándezAlonso, J. Varela-Mallou, and M. Suárez-Cunqueiro, "Anatomical characteristics and visibility of mental foramen and accessory mental foramen: panoramic radiography vs. cone beam CT," Medicina Oral Patología Oral Y Cirugia Bucal, vol. 20, pp. e707-e714, 2015.

[19] S.-S. Han, J. J. Hwang, and H.-G. Jeong, “Accessory mental foramina associated with neurovascular bundle in Korean population," Surgical and Radiologic Anatomy, vol. 38, no. 10, pp. 1169-1174, 2016.

[20] A. Safaee, S. Mirbeigi, F. Ezoddini, L. Khojastepour, and A. Navab-Azam, "Buccolingual course of the inferior alveolar canal in different mental foramen locations: a cone beam computed tomography study of an Iranian population," International Journal of Applied and Basic Medical Research, vol. 6, no. 4, pp. 262-266, 2016.

[21] J. Muinelo-Lorenzo, A. Fernández-Alonso, E. Smyth-Chamosa, J. A. Suárez-Quintanilla, J. Varela-Mallou, and M. M. Suárez-Cunqueiro, "Predictive factors of the dimensions and location of mental foramen using cone beam computed tomography," PLoS ONE, vol. 12, p. e0179704, 2017.

[22] H. Al-Mahalawy, H. Al-Aithan, B. Al-Kari, B. Al-Jandan, and S. Shujaat, "Determination of the position of mental foramen and frequency of anterior loop in Saudi population. A retrospective CBCT study," The Saudi Dental Journal, vol. 29, no. 1, pp. 29-35, 2017.

[23] M. Velasco-Torres, M. Padial-Molina, G. Avila-Ortiz, R. García-Delgado, A. Catena, and P. Galindo-Moreno, "Inferior alveolar nerve trajectory, mental foramen location and incidence of mental nerve anterior loop," Medicina Oral Patologica Oral Y Cirugica Bucal, vol. 22, pp. e630-e635, 2017.

[24] U. Krishnan, P. Monsour, K. Thaha, R. Lalloo, and A. Moule, "A limited field Cone-beam computed tomography-based evaluation of the mental foramen, accessory mental foramina, anterior loop, lateral lingual foramen, and lateral lingual canal," Journal of Endodontics, vol. 44, no. 6, pp. 946-951, 2018.
[25] F. Alsoleihat, F. A. Al-Omari, A. R. Al-Sayyed, A. A. AlAsmar, and A. Khraisat, "The mental foramen: a cone beam CT study of the horizontal location, size and sexual dimorphism amongst living Jordanians," Homo, vol. 69, no. 6, pp. 335-339, 2018.

[26] Y. Y. Bosykh, A. Y. Turkina, R. P. A. V. Franco, A. Franco, and M. K. Makeeva, "Cone beam computed tomography study on the relation between mental foramen and roots of mandibular teeth, presence of anterior loop and satellite foramina," Morphologie, vol. 103, no. 341, pp. 65-71, 2019.

[27] H. Sahman and Y. Sisman, "Anterior loop of the inferior alveolar canal: a cone-beam computerized tomography study of 494 cases," Journal of Oral Implantology, vol. 42, no. 4, pp. 333-336, 2016.

[28] M. Naitoh, K. Yoshida, K. Nakahara, K. Gotoh, and E. Ariji, "Demonstration of the accessory mental foramen using rotational panoramic radiography compared with cone-beam computed tomography," Clinical Oral Implants Research, vol. 22, no. 12, pp. 1415-1419, 2011.

[29] T. S. N. Imada, L. M. P. d. S. R. Fernandes, B. S. Centurion, C. de Oliveira-Santos, H. M. Honório, and I. R. F. RubiraBullen, "Accessory mental foramina: prevalence, position and diameter assessed by cone-beam computed tomography and digital panoramic radiographs," Clinical Oral Implants Research, vol. 25, no. 2, pp. e94-e99, 2014.

[30] F. S. Neves, M. C. C. Nascimento, M. L. Oliveira, S. M. Almeida, and F. N. Bóscolo, "Comparative analysis of mandibular anatomical variations between panoramic radiography and cone beam computed tomography," Oral and Maxillofacial Surgery, vol. 18, no. 4, pp. 419-424, 2014.

[31] A. Vujanovic-Eskenazi, J. Valero-James, M. Sánchez-Garcés, and C. Gay-Escoda, "A retrospective radiographic evaluation of the anterior loop of the mental nerve: comparison between panoramic radiography and cone beam computerized tomography," Medicina Oral Patología Oral Y Cirugia Bucal, vol. 20, pp. e239-e245, 2015.

[32] S. Kumbargere Nagraj, E. Prashanti, H. H. Kyaw Soe, K. Salian, D. Chien, and C. Lin, "Radiographic evaluation of the anterior loop of the mental nerve: comparison between orthopantomograph and cone-beam CT-a pilot study," Research Journal of Pharmaceutical, Biological and Chemical Sciences, vol. 8, p. 2044, 2017.

[33] R. Kastala, C. David, and N. Jayapal, "Momentousness of the mental loop: a comparative study," Contemporary Clinical Dentistry, vol. 10, no. 1, pp. 86-92, 2019.

[34] B. Shaban, A. Khajavi, N. Khaki, Y. Mohiti, T. Mehri, and H. Kermani, "Assessment of the anterior loop of the inferior alveolar nerve via cone-beam computed tomography," Journal of the Korean Association of Oral and Maxillofacial Surgeons, vol. 43, no. 6, pp. 395-400, 2017.

[35] C. Madrigal, R. Ortega, C. Meniz, and J. López-Quiles, "Study of available bone for interforaminal implant treatment using cone-beam computed tomography," Medicina Oral, Patologia Oral Y Cirugia Bucal, vol. 13, no. 5, pp. E307-E312, 2008.

[36] F. Parnia, E. Moslehifard, A. Hafezeqoran, F. Mahboub, and H. Mojaver-Kahnamoui, "Characteristics of anatomical landmarks in the mandibular interforaminal region: a conebeam computed tomography study," Medicina Oral Patología Oral Y Cirugia Bucal, vol. 17, pp. e420-e425, 2012.

[37] M. Sheikhi and M. K. Kheir, "СBCT Assessment of mental foramen position relative to anatomical landmarks," International Journal of Dentistry, vol. 2016, Article ID 5821048, , 2016. 
[38] J. C.-H. Chen, L.-M. Lin, J. R. Geist, J.-Y. Chen, C.-H. Chen, and Y.-K. Chen, "A retrospective comparison of the location and diameter of the inferior alveolar canal at the mental foramen and length of the anterior loop between American and Taiwanese cohorts using CBCT," Surgical and Radiologic Anatomy, vol. 35, no. 1, pp. 11-18, 2013.

[39] E. Gungor, O. S. Aglarci, M. Unal, M. S. Dogan, and S. Guven, "Evaluation of mental foramen location in the 10-70 years age range using cone-beam computed tomography," Nigerian Journal of Clinical Practice, vol. 20, no. 1, pp. 88-92, 2017.

[40] M. Naitoh, Y. Hiraiwa, H. Aimiya, K. Gotoh, and E. Ariji, "Accessory mental foramen assessment using cone-beam computed tomography," Oral Surgery, Oral Medicine, Oral Pathology, Oral Radiology, and Endodontology, vol. 107, no. 2, pp. 289-294, 2009.

[41] M. Sheikhi, M. Karbasi Kheir, and E. Hekmatian, "Cone-beam computed tomography evaluation of mental foramen variations: a preliminary study," Radiology Research and Practice, vol. 2015, Article ID 124635, 5 pages, 2015.

[42] M. K. Alam, S. Alhabib, B. K. Alzarea et al., "3D CBCT morphometric assessment of mental foramen in Arabic population and global comparison: imperative for invasive and non-invasive procedures in mandible," Acta Odontologica Scandinavica, vol. 76, no. 2, pp. 98-104, 2018.

[43] S. Goyushov, M. D. Tözüm, and T. F. Tözüm, "Assessment of morphological and anatomical characteristics of mental foramen using cone beam computed tomography," Surgical and Radiologic Anatomy, vol. 40, no. 10, pp. 1133-1139, 2018.

[44] E. Zmysłowska, M. Radwański, S. Ledzion, M. Łęski, A. Zmyslowska, and M. Łukomska-Szymańska, "Evaluation of size and location of a mental foramen in the polish population using cone-beam computed tomography," BioMed Research International, vol. 2019, Article ID 1659476, 8 pages, 2019.

[45] A. Kalender, K. Orhan, and U. Aksoy, "Evaluation of the mental foramen and accessory mental foramen in Turkish patients using cone-beam computed tomography images reconstructed from a volumetric rendering program," Clinical Anatomy, vol. 25, no. 5, pp. 584-592, 2012.

[46] L. Ritter, J. Neugebauer, R. A. Mischkowski et al., "Evaluation of the course of the inferior alveolar nerve in the mental foramen by cone beam computed tomography," International Journal of Oral Maxillofacial Implants, vol. 27, pp. 1014-1021, 2012.

[47] M. Gümüşok, Z. Z. Akarslan, A. Başman, and Ö. Üçok, "Evaluation of accessory mental foramina morphology with cone-beam computed tomography," Nigerian Journal of Clinical Practice, vol. 20, no. 12, pp. 1550-1554, 2017.

[48] C. Oliveira-Santos, P. H. C. Souza, S. De Azambuja BertiCouto et al., "Characterisation of additional mental foramina through cone beam computed tomography," Journal of Oral Rehabilitation, vol. 38, no. 8, pp. 595-600, 2011.

[49] M. Göregen, Ö. Miloğlu, I. Ersoy, I. Bayrakdar, and H. Akgül, "The assessment of accessory mental foramina using conebeam computed tomography," Turkish Journal of Medical Sciences, vol. 43, pp. 479-483, 2013.

[50] E. Aytugar, C. Özeren, N. Lacin, I. Veli, and E. Çene, "Conebeam computed tomographic evaluation of accessory mental foramen in a Turkish population," Anatomical Science International, vol. 94, no. 3, pp. 257-265, 2019.

[51] J. Iwanaga, K. Watanabe, T. Saga et al., "Accessory mental foramina and nerves: application to periodontal, periapical, and implant surgery," Clinical Anatomy, vol. 29, no. 4, pp. 493-501, 2016.
[52] T. Y. Yoon, A. G. Ahmadi, N. A. Saed, N. E. Estrin, D. E. Miller, and T. N. Dinh, "Prevalence and anatomical characteristics of the accessory mental foramen: a study using cone beam computed tomography," General Dentistry, vol. 67, pp. 62-67, 2019.

[53] F. Çağlayan, M. A. Sümbüllü, H. M. Akgül, and O. Altun, "Morphometric and morphologic evaluation of the mental foramen in relation to age and sex: an anatomic cone beam computed tomography study," The Journal of Craniofacial Surgery, vol. 25, no. 6, pp. 2227-2230, 2014.

[54] Y. Sisman, H. Sahman, A. Sekerci, T. T. Tokmak, Y. Aksu, and E. Mavili, "Detection and characterization of the mandibular accessory buccal foramen using CT," Dentomaxillofacial Radiology, vol. 41, no. 7, pp. 558-563, 2012.

[55] N. Raju, W. Zhang, A. Jadhav, A. Ioannou, S. Eswaran, and R. Weltman, "Cone-beam computed tomography analysis of the prevalence, length, and passage of the anterior loop of the mandibular canal," Journal of Oral Implantology, vol. 45, no. 6, pp. 463-468, 2019.

[56] L. Khojastepour, S. Mirbeigi, S. Mirhadi, and A. Safaee, "Location of mental foramen in a selected Iranian population: a CBCT assessment," Iranian Endodontic Journal, vol. 10, no. 2, pp. 117-121, 2015.

[57] Y. Li, X. Yang, B. Zhang, B. Wei, and Y. Gong, "Detection and characterization of the accessory mental foramen using conebeam computed tomography," Acta Odontologica Scandinavica, vol. 76, no. 2, pp. 77-85, 2018.

[58] M. Lam, C. Koong, E. Kruger, and M. Tennant, "Prevalence of accessory mental foramina: a study of 4,000 CBCT scans," Clinical Anatomy, vol. 32, no. 8, pp. 1048-1052, 2019.

[59] X. Wei, P. Gu, Y. Hao, and J. Wang, "Detection and characterization of anterior loop, accessory mental foramen, and lateral lingual foramen by using cone beam computed tomography," Journal of Prosthetic Dentistry, vol. S22, pp. 30494-30499, 2019.

[60] D. Yovchev, H. Mihaylova, P. Stanimirov, A. Gusiyska, and M. Dimova, "Incidence, location and sizes of the accessory mental foramina in Bulgarian population assessed by conebeam computed tomography," Biomedical Research, vol. 28, pp. 5122-5126, 2017.

[61] H. Eren, K. Orhan, N. Bagis, R. Nalcaci, M. Misirli, and E. Hincal, "Cone beam computed tomography evaluation of mandibular canal anterior loop morphology and volume in a group of Turkish patients," Biotechnology \& Biotechnological Equipment, vol. 30, no. 2, pp. 346-353, 2016.

[62] T. Koivisto, D. Chiona, L. L. Milroy, S. B. McClanahan, M. Ahmad, and W. R. Bowles, "Mandibular canal location: cone-beam computed tomography examination," Journal of Endodontics, vol. 42, no. 7, pp. 1018-1021, 2016.

[63] P. Christopher, T. Marimuthu, C. Krithika, P. Devadoss, and S. M. Kumar, "Prevalence and measurement of anterior loop of the mandibular canal using CBCT: a cross sectional study," Clinical Implant Dentistry and Related Research, vol. 20, no. 4, pp. 531-534, 2018.

[64] S. K. Wong and P. G. Patil, "Measuring anterior loop length of the inferior alveolar nerve to estimate safe zone in implant planning: a CBCT study in a Malaysian population," The Journal of Prosthetic Dentistry, vol. 120, no. 2, pp. 210-213, 2018.

[65] Z. D. Kajan and A. Salari, "Presence and course of the mandibular incisive canal and presence of the anterior loop in cone beam computed tomography images of an Iranian population," Oral Radiology, vol. 28, no. 1, pp. 55-61, 2012. 
[66] K. Filo, T. Schneider, M. C. Locher, A. L. Kruse, and H.-T. Lübbers, "The inferior alveolar nerve's loop at the mental foramen and its implications for surgery," The Journal of the American Dental Association, vol. 145, no. 3, pp. 260269, 2014.

[67] D. Apostolakis and J. E. Brown, "The anterior loop of the inferior alveolar nerve: prevalence, measurement of its length and a recommendation for interforaminal implant installation based on cone beam CT imaging," Clinical Oral Implants Research, vol. 23, no. 9, pp. 1022-1030, 2012.

[68] Y. Uchida, N. Noguchi, M. Goto et al., "Measurement of anterior loop length for the mandibular canal and diameter of the mandibular incisive canal to avoid nerve damage when installing endosseous implants in the interforaminal region: a second attempt introducing cone beam computed tomography," Journal of Oral and Maxillofacial Surgery, vol. 67, no. 4, pp. 744-750, 2009.

[69] M. Naitoh, K. Nakahara, Y. Suenaga, K. Gotoh, S. Kondo, and E. Ariji, "Comparison between cone-beam and multislice computed tomography depicting mandibular neurovascular canal structures," Oral Surgery, Oral Medicine, Oral Pathology, Oral Radiology, and Endodontology, vol. 109, no. 1, pp. e25-e31, 2010.

[70] C.-I. Lu, J. Won, A. Al-Ardah, R. Santana, D. Rice, and J. Lozada, "Assessment of the anterior loop of the mental nerve using cone beam computerized tomography scan," Journal of Oral Implantology, vol. 41, no. 6, pp. 632-639, 2015.

[71] M. Panjnoush, Z. S. Rabiee, and Y. Kheirandish, "Assessment of location and anatomical characteristics of mental foramen, anterior loop and mandibular incisive canal using cone beam computed tomography," Journal of Dentistry (Tehran), vol. 13, pp. 126-132, 2016.

[72] E. Zmysłowska-Polakowska, M. Radwański, M. Łęski, S. Ledzion, M. Łukomska-Szymańska, and M. Polguj, “The assessment of accessory mental foramen in a selected polish population: a CBCT study," BMC Med Imaging, vol. 17, p. 17, 2017.

[73] B. S. Chong, K. Gohil, R. Pawar, and J. Makdissi, “Anatomical relationship between mental foramen, mandibular teeth and risk of nerve injury with endodontic treatment," Clinical Oral Investigations, vol. 21, no. 1, pp. 381-387, 2017.

[74] X.-w. Yang, F.-f. Zhang, Y.-h. Li, B. Wei, and Y. Gong, "Characteristics of intrabony nerve canals in mandibular interforaminal region by using cone-beam computed tomography and a recommendation of safe zone for implant and bone harvesting," Clinical Implant Dentistry and Related Research, vol. 19, no. 3, pp. 530-538, 2017.

[75] L. Marieiro, D. Deluiz, D. Ferreira, and P. Tannure, "Measurement of distance between the mental foramina using cone beam computed tomography: a pilot study with a possible method for planning mandibular implants," Pesquisa Brasileira em Odontopediatria e Clínica Integrada, vol. 17, no. 1, pp. 1-6, 2017.

[76] M. R. Moghddam, Z. Davoudmanesh, N. Azizi, V. Rakhshan, and M. Shariati, "Prevalence and length of the anterior loop of the inferior alveolar nerve in Iranians," Journal of Oral Implantology, vol. 43, no. 5, pp. 333-336, 2017.

[77] G. Aoun, A. ElOuta, N. Kafrouny, and A. Berberi, "Assessment of the mental foramen location in a sample of fully dentate Lebanese adults using cone-beam computed tomography technology," Acta Informatica Medica, vol. 25, no. 4, pp. 259-262, 2017.

[78] M. Kheir and M. Sheikhi, "Assessment of the anterior loop of mental nerve in an Iranian population using cone beam computed tomography scan," Dental Research Journal, vol. 14, no. 6, pp. 418-422, 2017.

[79] M. do Carmo Oliveira, T. K. Tedesco, T. Gimenez, and S. Allegrini, "Analysis of the frequency of visualization of morphological variations in anatomical bone features in the mandibular interforaminal region through cone-beam computed tomography," Surgical and Radiologic Anatomy, vol. 40, no. 10, pp. 1119-1131, 2018.

[80] C. L. Vieira, S. d. A. R. Veloso, and F. F. Lopes, "Location of the course of the mandibular canal, anterior loop and accessory mental foramen through cone-beam computed tomography," Surgical and Radiologic Anatomy, vol. 40, no. 12, pp. 1411-1417, 2018.

[81] L. Xie, T. Li, J. Chen, D. Yin, W. Wang, and Z. Xie, "Conebeam CT assessment of implant-related anatomy landmarks of the anterior mandible in a Chinese population," Surgical and Radiologic Anatomy, vol. 41, no. 8, pp. 927-934, 2019.

[82] S. Valdec, J. M. Borm, S. Casparis, G. Damerau, M. Locher, and B. Stadlinger, "Vestibular bone thickness of the mandible in relation to the mandibular canal-a retrospective CBCTbased study," International Joural of Implant Dentistry, vol. 5, p. 37, 2019.

[83] G. Juodzbalys, H.-L. Wang, and G. Sabalys, "Injury of the inferior alveolar nerve during implant placement: a literature review," Journal of Oral and Maxillofacial Research, vol. 2, no. 1, p. e1, 2011.

[84] W. Cheong Ngeow, "Is there a "safety zone" in the mandibular premolar region where damage to the mental nerve can be avoided if periapical extrusion occurs?" Journal of Canadian Dental Association, vol. 76, p. a61, 2010.

[85] A. B. G. Tay and J. R. Zuniga, "Clinical characteristics of trigeminal nerve injury referrals to a university centre," International Journal of Oral and Maxillofacial Surgery, vol. 36, no. 10, pp. 922-927, 2007.

[86] A. A. Alhassani and A. S. T. AlGhamdi, "Inferior alveolar nerve injury in implant dentistry: diagnosis, causes, prevention, and management," Journal of Oral Implantology, vol. 36, no. 5, pp. 401-407, 2010.

[87] V. B. Ziccardi and L. A. Assael, "Mechanisms of trigeminal nerve injuries," Atlas of the Oral and Maxillofacial Surgery Clinics, vol. 9, no. 2, pp. 1-11, 2001.

[88] R. Weiss and A. Read-Fuller, "Cone beam computed tomography in oral and maxillofacial surgery: an evidencebased review," Dentistry Journal, vol. 7, pp. 1-23, 2019.

[89] C. Angelopoulos, S. Thomas, S. Hechler, N. Parissis, and M. Hlavacek, "Comparison between digital panoramic radiography and cone-beam computed tomography for the identification of the mandibular canal as part of presurgical dental implant assessment," Journal of Oral and Maxillofacial Surgery, vol. 66, no. 10, pp. 2130-2135, 2008.

[90] A. Aminoshariae, A. Su, and J. C. Kulild, "Determination of the location of the mental foramen: a critical review," Journal of Endodontics, vol. 40, no. 4, pp. 471-475, 2014.

[91] Y. Uchida, Y. Yamashita, M. Goto, and T. Hanihara, "Measurement of anterior loop length for the mandibular canal and diameter of the mandibular incisive canal to avoid nerve damage when installing endosseous implants in the interforaminal region," Journal of Oral and Maxillofacial Surgery, vol. 65 , no. 9, pp. 1772-1779, 2007. 